\title{
Making MadLab: A creative space for innovation and creating prototypes
}

\author{
Authors \\ Frances Bell - University of Salford \\ Gordon Fletcher* - University of Salford \\ Anita Greenhill - University of Manchester \\ Marie Griffiths - University of Salford \\ Rachel McLean - Liverpool John Moores University \\ * Corresponding Author \\ Email: G.Fletcher@salford.ac.uk \\ Telephone: 01612955851 \\ Fax: 01612955022
}




\section{Making MadLab: A creative space for innovation and creating prototypes}

\section{Abstract}

This paper presents Manchester Digital Laboratory (MadLab) as an "organization as prototype" in terms of its innovation; emphasizing its permeability to external collaboration and internal structure. We present the accumulation of experience and inspiration found in this organisational prototype as a significant development with as much social impact as any single material invention. Few organisations are held up as examples of organisational prototypes although notable exceptions such as Apple Computers and Factory Records do exist. Few of these examples offer a systematic accounting for the basis of organisational innovation and its application elsewhere. This work sets out to understand how inspirations drawn from sources such as literature and popular media and seemingly disparate personal ideas and skills, through processes of invention and innovation can become the basis for a sustainable organisation capable of creating value. In this manner we present MadLab as a prototype that is the product of the personal interests and motivations of the directors and their influences - including science fiction. While the directors did not consciously engage in Science Fiction Prototyping we present their actions, organisational structure and collaboration as a model for the realisation of organisational Science Fiction Prototyping. This empirical study focuses on MadLab; its short history, its people, its activities and the intersecting creative influences on the different groups that make up the organisation. The understanding gained of this organisational prototype is then considered within a more generalised view of organisation types and their potential to create value and achieve long-term viability.

Keywords: Innovation; Creative Prototyping; Organisational Prototypes; Manchester Digital Laboratory - MadLab; Visionary Management 


\section{Introduction}

The theoretical foundation for this paper begins by extending earlier work (Bell et al. 2013) that drew upon Mannermaa's (1991) paradigmatic trinity of futures research. These works articulate a dynamic relationship between inspiration, innovation and prototypes and the role of these activities within an organisation's management. Johnson's (2011) description of a prototype also helps to guide our work.

A prototype is a story or fictional depiction of a product. The prototype is not the actual thing that we want to build; it is an example, a rough approximation of the thing we hope to one day build (Johnson 2011: 12).

Johnson's (2011) definition realises the prospect for intangible and conceptual forms of prototypes moving away from the need for tangible 'things'. It is from this definition of prototype by Johnston (2011) that we are able to explore the 'organisation as prototype'.

Thus in reflective empirical research the centre of gravity is shifted from the handling of empirical material towards, as far as possible, a consideration of the perceptual, cognitive, theoretical, linguistic, (inter)textual, political and cultural circumstances that form the backdrop to - as well as impregnate - the interpretations (Alvesson \& Sköldberg, 2009).

In contrast to classic models of strategy and organisational change that adopt a top down, planned approach, there are other inductive, reflective and emergent approaches that permit innovation to emerge from a reflexive context. To interpret this realisation Mintzberg (1978) distinguished between deliberate (intended and realised), unrealised (intended but not realised because of misinterpretation or changes in expectations or environment) and emergent (realised but not intended) strategies. Strategy formation can be seen as an agreed organisational response to predicted forms of the medium-term future that are tested through a series of formal or informal scenarios. Incremental changes to these strategies take place in response to unexpected changes (Bell et al., 2013) with the active acknowledgement that, "in such a world, strategic plans, where they exist have a short half-life." (Sauer and Willcocks 
2003: 507). When circumstances are turbulent or previous assumptions have become inappropriate, emergent strategy formation is recommended (Mintzberg, 1978), although emergent strategies themselves are unlikely to be discrete and complete solutions (Mintzberg, 2003). Emergent design for organisational change focuses on reflective sense-making (Weick, 2001) and emergent strategy fosters learning (Mintzberg, 2003). The manager who wishes to do strategy formation well will necessarily "require an open mind, a recognition of how little we really know, and intensive, painstaking research." (Mintzberg, 1978: 948).

Figure 1: Forms of management and their relationship to prototypes and innovation (adapted from Bell et al 2013).

The model arrangement of organisational forms of management (Figure 1), developed by the authors in Bell et al (2013) and extended here, was originally used to explore the role that science fiction prototypes play within future innovations. The findings showed that innovation is most often revealed as a prototype and can be described as being a specific case of visionary management. In this current study we extend the origins and purpose of the model to examine the role of speculative- and science-fiction as a driver of personal inspiration that in turn influences an innovating and creative organisation. We specifically explore MadLab as an 'organisation as prototype' where vision, innovation and inspiration potentially combine with dayto-day operational realities to construct a strategically sustainable environment. As an 'organisation as prototype' MadLab continuously tests the vision and inspirations of its directors and challenges them to construct an organisation that balances the demands of operational, strategic and visionary management.

\subsection{Introducing MadLab}

MadLab, short for the Manchester Digital Laboratory, is an inspired community space for science, technology and art based in Manchester's City Centre. The 'space' is 3,000 sq. ft. of 
premium real estate based in the Northern Quarter, a recently gentrified area in the centre of Manchester, England that is popularly regarded as a centre for alternative and bohemian culture. The location of MadLab lends itself to comparisons with Andy Warhol's New York studio, The Factory, as a hub that attracts artistic, free thinking individuals. MadLab, as a not-for-profit organisation, describes itself as "community space for people who want to do and make interesting stuff - a place for geeks, artists, designers, illustrators, hackers, tinkerers, innovators and idle dreamers; an autonomous Research \& Development laboratory and a release valve for Manchester's creative communities". Established in 2008, it is a relatively young enterprise that has stamped a mark on the digital creativity community in Manchester. MadLab has a sense of its own organisational identity and a clear ethos, that is revealed by their answer to the rhetorical question, "Why MadLab?"

To confirm Manchester's rightful place as the home of technical and creative innovation and invention in the North West and beyond; to bring together the various communities of doers and thinkers that make this city brilliant and see what comes of it; to build interesting things that inspire others; and most important of all, because it's fun (madlab.org.uk/about/).

We have focused on MadLab's history, structures and personal histories of its four directors in order to explore the extent to which narratives of fiction are drawn upon for inspiration, even if the story has ultimately diverged from those futures originally envisioned by the founders. We examine the inspiration of science fiction stories to the development and realisation of future business visions, applications and developments associated with the visions found in the MadLab story. Johnson (2011) notes that the goal of Science Fiction Prototypes is to start a conversation about technology and the future, giving people a "language" through which to communicate about an imagined future, its products, services and technologies. Further support for this claim is found in Dourish and Bell (2009: 1) who suggest that "science fiction in popular culture provides a context in which new technological developments are understood". 
We argue that science- and speculative-fiction play a role in stimulating personal creativity and inspiration through a process that directly, but subtly, informs 'organisation as prototype' design. Drawing upon the vignette of MadLab we see the innovation that this induces as being positioned between the intersecting demands of strategic, operational and visionary forms of management and ultimately contributing to the long-term success of an organisation. With this perspective we are employing an amorphous view of the organisation (sometimes disparagingly described as Mintzberg's cloud) to acknowledge the many ways in which innovation and inspiration do not respect organisational or internal boundaries as well as offering explanation as to why some organisations are considered 'more' innovative. In this way we present an interpretation of innovation and prototyping that is constructive, generalisable and ultimately intended as useful for other organisations. Further, the paper makes a valuable contribution by recommending for more cross-disciplinary internal and external collaborations that lead to the realisation and commercialization of inspiration and innovation.

To structure our argument and in recognition of the close inter-relationship between organisational form and the ability to innovate we extend the relational model between science fiction prototyping and forms of organisational management that was proposed in Bell et al (2013). A limitation of this earlier paper was its near exclusive attention to the relationship between science fiction prototypes and identification of their later realisation in actuality. This focus emphasised a clear temporal distance between fiction 'as prototype' from its later contribution as inspiration to the operationalisation of a prototype. The separation of fiction as inspiration and the prototype that is inspired by it produces a clarity in their relationship. However, within the practicalities of a contemporary creative organisation such neat distancing is not always so readily found between the source of inspiration and the pressure to operationalise the prototype. 
In her extensive work on creativity, Amabile (1996) has made a strong case for adopting a social perspective on creativity. Amabile (1996: 5) highlighted that previous studies in the field had focused on the personalities of creative individuals. This echoes what Mintzberg et al. (1998) call the "Entrepreneurial School: Strategy Formation as a Visionary Process", in which strategy research focuses on 'vision'; with specific concern directed to the mental representation of a strategy by the individual entrepreneur. Vision is loosely articulated and flexible, leaving it open to change in response to experience and environment and is therefore both deliberate and emergent (Mintzberg, Ahlstrand, \& Lampel, 1998). In conjunction with vision is the need for fluidity, reflective capability and an ongoing openness to strategic change as hallmarks of organisational success in small innovating organisations. This can be evidenced with business and Information Technology (IT) innovations in small-medium sized enterprises (SMEs) where the benefits brought by envisioning and inductively re-visioning can be clearly identified (Ferneley \& Bell, 2006). Actively adopting a clearly social perspective in relation to innovation and prototyping enables consideration of factors including the work environment and its major influence on the creativity of workers in organisations. In their work, Shalley \& Gilson (2004) show the importance of social and contextual factors as key tenets for success and specifically describe them in the forms of product, process, person and situation (Woodman, Sawyer, \& Griffin, 1993). This combination of factors that contribute to a successful innovating organisation can be found in the example of MadLab. We find among the directors specific personal visions of the organisation, a dynamic and responsive organisational structure placed within an environment that maximizes access to external collaborations and individuals.

\section{Method}

In order to carry out the study, build the vignette and understand the relationship of forms of management to the 'organisation as prototype', the research team employed a case study approach to gather data. None of the researchers had previous contact with MadLab and only 
became aware of its presence through the many collaborative organisational alliances that had already been forged by MadLab. The significant media presence that has been self-generated by MadLab (section 7) provides a broad understanding of the purpose and vision of MadLab as well as providing some insight into the individual background and inspirations of each of the four directors. To understand the organisation, its operations, management practices and future visions the researchers conducted interviews with the directors through a combination of email exchanges, telephone and Skype conversations along with face-to-face meetings. These interactions were largely unstructured with generally a single question from the researchers initiating a conversation varying from between a few minutes to multiple hours. It was seen as important by the researchers to conduct some of the interactions with the directors in situ in their familiar environment. The actual space of MadLab, is core to the ongoing shaping of the director's vision so, in order to reflect this influence, key aspects of the data collection was conducted in this space to absorb and observe the interactions. Two unstructured interviews were conducted in the central community area of MadLab. This is a much-used space with a muddle of furniture and ad hoc pieces of donated computer hardware amid various on-going projects and experiments. The unstructured interviews were recorded with the permission of the directors and they also showcased a number of their previous projects via physical artefacts, websites, printed materials and photographs. Two other interviews were conducted and recorded in a local café near MadLab and again this venue offered further insight as to how embedded the directors are in the local community. Three Skype interviews were also conducted with one director who was out of the country at the time of the data collection period. We were also given permission to record these interviews.

Further secondary research materials regarding MadLab were garnered from online artefacts relating to the organisation including photo galleries, social media presence and references by other organisations to MadLab and their collaborations. This interconnectivity of Internet based 
material and web archives provided a rich and vivid backdrop to the physical MadLab space and the 'organisation as prototype' that has evolved and positioned itself in the digital architecture of Manchester. A combination of observational and textual analysis was conducted on this collected Internet based material and correlative links were identified and drawn upon to provide background data for the vignettes and organisational analysis.

\section{The Vignette}

\subsection{The Background}

MadLab is a hybrid space, an environment for the 'nebulous three stage period' of creativity. It could be described formally as a Technical and Scientific Service (TSS) organisation that provides innovators supporting services and infrastructure to realise their imagination. This definition is somewhat overly formal and precise. MadLab is a cultural organisation encapsulating and extending a hackerspace - and vice versa. This makes MadLab a prototype for other creative organisations in its own right. It is not solely positioned as the domain of technicians with an idea nor is it simply a space for hacker groups. The venue does host a hackerspace-type group but it has also been the host to sub-cultural groups such as Manchester's gothic community and formally recognised national organisations such as the Chartered Institute for IT, the British Computer Society, as well as a science fiction reading group and a speculative fiction creative writing group. This vignette introduces MadLab's directors, individuals and groups, who have shown a willingness to explore their inspirations, share their visions, to innovate and to operationalise these thoughts.

MadLab also hosts a range of innovative projects - some externally funded and others that are not. The current list of projects provides an indication of the diversity of interests that are hosted and represented within the organisation. This is further evidence that MadLab is not solely positioned in the domain of computer 'geeks' exploring esoteric projects or engaging solely in 
solipsism. For example, Patchworks is a project run in conjunction with Lancaster University, with the aim of developing self-diagnostic tools for hard-to-reach and homeless communities. MadLab is providing the technological and biological know-how and originally proposed the project. The idea for Patchworks itself came from MadLab's "do-it-yourself biology" project, DIYbioMCR. The biggest community lab space in the UK, where people can access Polymerase Chain Reaction (PCR) machines, gel boxes, 3D scanners and other equipment. MadLab is preparing to become Biosafety Level 1 (BSL1) rated as a commitment to the DIY aspect of their lab provision and extending the safety of citizen participation within its own facilities. This is the lowest level of biosafety containment but nonetheless an unique European Union certification for a community based organisation of any type. Once this rating is achieved it will make MadLab the first community lab in Europe to have recognition of this type. HacMan are a collective of engineers, tinkerers and technology enthusiasts whose creations use new technology in a playful and interactive way. The collective have made a "Twitter Drum" that plays a different tune every time it gets mentioned on Twitter, a "Knock Clock" - a wooden box that taps the time back when hit, a life-size game of "Operation" and a giant Etch-a-Sketch (the Project-a-Sketch). HacMan have made interactive installations for an NHS children's hospital and are currently commissioned to make a piece for HM Prison Manchester (more regularly referred to as Strangeways). MadLab have hosted "Young Rewired State" for the last three years. This is a growing national initiative to improve coding skills among young people. Past alumni have been offered work placements in Silicon Valley in California and the Silicon Roundabout (Old Street) in London. MadLab is currently working on a new strand for this project, developing schemes with several partner organisations such as the Manchester and Salford City Councils and Ogilvy \& Mather to plug the well-recognised IT skills gap currently within schools. There are many other smaller, individual projects such as Kinokophonography - a sound recording project - that have 'grown up' from the MadLab environment. 
The vignette presented here assists in the documentation of the history and success of the organisation; as well as providing examples of an organisational space for innovation; and an example of how innovations and future visions which may appear to be science fiction are influencing work and collaboration in Manchester's business and technology domain.

The vision of MadLab is clearly attractive and has received support across a wide range of organisations. But support does not bring direct success and the concept of MadLab has been described both as desirable and at the same time as 'unfundable' by one potential funder. The fact that MadLab's initial financial support came from UK Government sourced funding introduces a range of stakeholders that mirror the structure and operations of arts organisations but extend across innovation and technology organisations and groups as well as universities and science organisations. In its first year MadLab was self-funded by the directors, this predominately was their time given freely with a small amount of funding for the delivery of accessible adult learning. This input of labour and funds was used to supply the immediate needs for technology and equipment. The Manchester Digital Development Agency (MDDA) supplied free Wi-Fi to MadLab who in turn offered the same free Wi-Fi to the local nearby community. A hallmark of MadLab's role as an 'organisation as prototype' is its own willingness to explore opportunities and its encouragement for partner stakeholders to express this same willingness.

It is within this complex space that we find the processes of innovation and the intersections of opportunities and happenstance that brings together people, ideas and skills. MadLab's directors say, "we consider, in particular, the sources of inspiration prior to prototyping, modeling or the tangible articulation of solutions to perceived problems". This study explores comments and observations gathered from the directors, external organisations, such as the Manchester City Council, and the groups who have used MadLab to create individual projects within the 
space. We concentrate our investigation particularly around the influences that the various interest groups have upon one another through common membership, idea sharing or other types of proximity. Groups such as "Manchester Speculative Fiction" are examples of the potential influence of forms of fiction on the processes of invention and creation being undertaken within MadLab. However, other science fiction elements are identifiable in more subtle forms across the range of MadLab activities.

\subsection{The Vignette: MadLab}

A key aspect for this vignette is the individual biographies of the four directors. Each brings a unique combination of experiences and skills to MadLab that are complementary and reach across different sectors and disciplines. While this combination cannot be claimed as the sole parameter for the success of MadLab it is clearly contributory and a unique combination. MadLab's four directors are composed of two couples in their personal lives. This fact is mentioned only for the purpose of understanding how the relationships of the directors are potentially key to understanding how the organisation is managed. All four directors met at University while they were studying. Because of these personal relationships it is difficult to unravel a specific MadLab timeline as both couples' relationships were established prior to setting up the community space and shared similar sets of interests. It was the inspiration of MadLab that brought the four together. Two of the directors, met at the North West Ruby Users Group (NWRUG) in the middle of 2007. The NWRUG is based in Manchester and is home to a group of like-minded individuals who have an interest in the Ruby programming language. During these NWRUG group meetings they shared their motivations and ideas for creating a community space in Manchester inspired by their experiences and observations of other spaces in other cities including London. This influence presents an insight into the directors - given that two are active coders - and that coding initially formed a large part of what MadLab was, a hackspace. Conversations seeking to unpick underlying inspirations with both of these directors 
hint at an influence of science fiction through exposure to popular media, however, pressing either director suggests that this is a deeply embedded awareness but not one that was directly articulated in the original vision of MadLab itself - it was, in one sense, always there but unspoken. This indefinite relationship can be understood partly through the moderating influence of the four directors' inspiration in combination. The broader mission of MadLab beyond being a hackspace is a combination of circumstances, with the intersection of interests of each director being discretely different but sufficiently connected enough to be complementary and to continue to drive the organisation.

\section{Director A.}

Director A's scientific interests at MadLab are very visible in the diverse projects that are championed and sustained by the directors. There is an experimental stimulus that MadLab conveys, the word 'Lab' in their name for example, and the sense that what they are doing as a group is unconventional. What underpins Director A's scientific projects is the overwhelming belief that the combination of art and science will democratize access to science for all communities and interested individuals. Although Director A makes no great claims regarding how he formed his worldview, he is an avid sci-fi fiction reader and singles out Philip K. Dick and William Gibson as two influential authors. Interestingly, the science fiction of Gibson and Dick is sociological and political, where technology is not the most prominent feature of the narrative. Their work tends to display dystopian themes and regarding parts of society as disenfranchised and disregarded. Such themes closely echo Director A's beliefs, particularly in his aspirations to build an inclusive culture of science for all. Director A describes himself as a creative technologist and DIY biologist (more detail of these projects are reported later in this section). His recent work has been closely tied to the development of the DIYbioMCR project and its parent project the ESPRC funded Catalyst project carried out in collaboration with Lancaster 
University. Director A is also a social media experimenter and networker, who is highly visible in despite his relatively low personal usage of popular and niche social networks.

\section{Director B}

Director $\mathrm{B}$ is an international journalist and ex-BBC producer who has broadcasting experience within the scientific genre. This connection inspires her current interests at MadLab through the DIYbioMCR project as a forum for amateur biologists that has earned MadLab a level of national and international notoriety. So much so, that in 2013 the FBI invited Director B and Director A to their centre in California as part of the Manchester City Council's contingent to share knowledge on DIY biology. Given that MadLab is still a relatively new organisation there is an established and mature online presence including a well visited website and message boards as well as an active blogosphere and over 5000 followers on Twitter. This is further evidence for MadLab's use of the wide in-house skill-set and expertise. Director B's 15 years of experience in broadcasting clearly contributes significantly to the MadLab digital profile and media presence. Director B also gives value to the adage that any publicity is good publicity even when the BBC's Radio Four ran sensationalist stories about MadLab's DIY technology projects. A number of different journalists claimed that MadLab was a dangerous laboratory where amateur scientists were re-creating Smallpox and Cholera and even genetically modifying pathogens. This is Director B's reference discipline and one in which she is well versed and able to maneuver any media interaction into a positive piece of public relations. It was Director B who found MadLab's building and negotiated successfully with the landlord for a very positive leasing agreement. This personal success is further evidence of how the directors play to their strengths in an almost spontaneous manner, having an experienced broadcaster and journalist with media acumen as a director has reinforced MadLab's positive and specialist reputation while fuelling an almost celebrity-like status among Manchester organisations.

\section{Director C}


Director $\mathrm{C}$ now focuses solely on her role at MadLab. She trained as a graphic designer and moved into interactive web and mobile design specialisms. She is a 'creative' in the conventional sense; always wanting to create and to 'do her own projects and make stuff', Director $\mathrm{C}$ believes that many designers share this sentiment and that that ultimately is why Manchester is becoming an internationally recognised hub for innovation and creativity and has a thriving digital scene. Director $\mathrm{C}$ and Director $\mathrm{D}$ were based in London and the pair utilised the creative spaces that were available to them while they lived there. They moved to Manchester and missed the open creative spaces such as Dorkbots based in Limehouse. Dorkbots is an influential and inspirational space for the directors' own imagining of MabLab to be a community space for those interested and wanting to foster discussion, share ideas and concepts in arts based technology projects. Director $\mathrm{C}$ also gives some acknowledgement to the inspiration of fiction - rather than science fiction more narrowly - in her work. Her direct involvement in and encouragement of the development of the science fiction reading group and its partnership with the City Council's library service are equally an active recognition of her interest in the genre but equally a reflection of her desire to read more deeply. This does mean that the influence of science fiction for Director $C$ is an ongoing and reciprocating inspiration for her other management activities associated with MadLab.

\section{Director D}

Director D was part of an art collective for two years in London; a creative and living warehouse space in Islington and a space that housed local artist's exhibitions and events. When Director D returned to Manchester he missed the cultural sustenance and was fortunate in meeting Director A who held a similar ambition to establish a creative community space. The consequence was the establishment of MadLab in 2007. Director D continues to deliver activities and events at MadLab while also holding a Fellowship at the University of Salford that situates him at the BBC R\&D department based in MediaCityUK, Salford. Speaking directly with 
Director $D$ soon reveals the extent that science fiction has played a part in developing his worldview. Director D draws ready reference to his current interest and activities from a range of the 'hard' science fiction authors such as Asimov but is equally familiar with authors considerable more 'social' in their outlook including Heinlein. But to suggest that these references are primary motivators for Director $D$ would be a significant overstatement. Science fiction is a source of personal inspiration that forms part of the unique combination of knowledges Director D brings to MadLab.

\section{The Groups and Communities}

Director C strategically constructs MadLab's profile by 'seeding' diverse community groups. Realising that she cannot run every new group herself, she encourages and facilitates new partnerships by finding the right people to champion groups. Has she got an ultimate vision for the groups that find a home with MadLab? 'Emphatically no', the MadLab portfolio of groups and users is left to chance. Her role is as a facilitator providing encouragement and providing the space for value creation. While the individual profiles, backgrounds and creative histories of the individual directors provide an important contribution to MadLab's operational continuity as a creative space it is the combinations of groups and communities who actively contribute to the space that is the source of Madlab's organisational vibrancy.

At the beginning of MadLab's existence it was not very difficult to attract 'traditional' digital groups as they were already quite active in Manchester. For example, the WordPress Group, the Ruby Group and Geek-up had shared membership and had designated days for meeting in order to avoid calendar clashes with each other. Director $\mathrm{C}$, who does not regard herself as a true 'geek', subsequently observed that MadLab's profile was 'too geeky' and too male. This demographic imbalance became a driver for introducing the Science-Fiction Book Club. This was both a strategic decision by this director built in response to an observed operational gap a 
reflection of the constant cycle of interaction between forms of management that is occurring at MadLab. The specific aim of the new Sci-Fi book club group, supported by Manchester Central Library was to introduce more women to MadLab. Manchester Central Library, at the same time, held a different but complementary aim in that the target group of 25-40 year old males are generally regarded as one of the hardest demographic group to attract into using libraries. This mutual need was the foundation for an intra-organisational relationship of mutual benefit that has been successful and is ongoing. MadLab now produces a six-monthly reading list of sci-fi novels. The library, in turn, buys ten copies of each nominated title for the book club, and these books are then returned into the library catalogue for general borrowing. As a result of this collaboration the accessible science-fiction content of Manchester's Library Service is now effectively being guided by MadLab and its book club. The science-fiction book club has therefore directly helped and expanded MadLab's profile by broadening out its range of services and capabilities, and by showcasing the public benefit such collaborations provide. The activity of reading has also encouraged a speculative writing group to emerge, extending the remit of interest to a wider and more contemporary genre. The presence of the Sci-Fi book club and the reading group also has expanded online with ongoing discussions that extend the face-to-face focus of book groups (e.g. madlab.org.uk/content/scifi-discussion-embassytown/).

Another of the active Madlab community projects is DIYbioMCR. This group is 'dedicated to making biology an accessible pursuit for citizen scientists, amateur biologists and biological engineers who value openness and safety'. The story so far has been an overwhelming success with hundreds of new biologists conducting practical experiments such as carrying out a full biological survey of Manchester's public places. This activity resulted in the making of fuel cells powered by bacteria from soil extracted from National Car Parks (a UK company that manages inner city car parking building). The group have also gathered swabs of bus stops to calculate 
how many bacteria colonies are present and analysed the DNA coding of sushi to identify the origins of the fish content.

In addition to the groups and communities that make up Madlab, creative spaces are also an important element of the organisation. For example Madlab has established itself as an Exhibition Space, within the Northern Quarter of Manchester's dynamic art scene. The development of Madlab as an exhibition space was brought about by coincidence when a Korean friend of Director C's loaned a collection of artworks to Madlab and through Director C's commitment to art and in her role as a director in the organisation Madlab opened its space to display the collection. The displaying of the artwork and exhibition gained momentum and through consensus cemented MadLab as an exhibition space for reputable high profile annual festivals that visit Manchester. These exhibitions now include festivals such as the annual Abandon Normal Devices (AND).

Apart from creative spaces Madlab also host a diversity of training and professional development activities, some of these offerings encompass its more clearly commercial operations. Omniversity is the professional training arm of MadLab. Short courses are offered in the evenings and on weekends covering a range of topics and specialisms that are not otherwise presented by other commercial bodies. These courses tend to focus upon more applied or directed training. For example, the intermediate Wordpress group offers a course on setting up an e-commerce site via this blogging/content management system. The course targets relatively underexplored aspects of web-applications and is run by one of the cofounders of the Wordpress group. Similarly, Madlab offers a visualisation training course that covers the use of the VVVV software and provides those attendees - who have access to suitable equipment - with the capacity to create '4D' building-scale projection performances. 
Additional groups utilising MadLab are presented in Table 1. The detail of the philosophies and perspectives found in each group reveal the range of skills and knowledges present. The breadth of perspectives and philosophies are indicative of the openness, inclusiveness and the creativity associated with MadLab. It is this feature of openness and external permeability of MadLab's 'organisation as prototype' that is of particular significance in the establishment and ongoing sustainability of other similar organisations. Coupled with the intersecting and combining permutations of operational activity and the varying philosophies of the directors, the participating community groups and the collaborating external organisations offers up a generalisable 'organisation as prototype' for others. Similar organisations can find a level of operational, strategic and visionary inspiration from the MadLab experience.

\begin{tabular}{|l|l|}
\hline Philosophy/Focus & Groups \\
\hline DIYbio/Political & $\begin{array}{l}\text { Home-made 'agar dishes': Make your own 'meal' and } \\
\text { see what bacteria grows on your plate. }\end{array}$ \\
\hline $\begin{array}{l}\text { DIYbio/Creative Technologist } \\
\text { Group }\end{array}$ & Bacterial Painting Workshop \\
\hline Hack/Political & iOS Manchester \\
\hline Hack/Political & Free Software Foundation Europe \\
\hline Hack/Creative Technologist Group & 3D photography \\
\hline Hack/Political & Windows Phone User Group \\
\hline Hack & North West Drupal User Group \\
\hline Hack/Creative Technologist Group & Manchester Google Technology Group \\
\hline Creative Technologist Group & Advanced CSS \\
\hline Creative Technologist Group & Raspberry Jam \\
\hline Creative Technologist Group & Geek Girls \\
\hline Literature Group & Mad Graphic Novel Group \\
\hline
\end{tabular}




\begin{tabular}{|l|l|}
\hline Literature Group & Poetry Writing Workshop \\
\hline Literature Group & Speculative writing Group \\
\hline Literature Group & Sci-Fi Book club \\
\hline Creative Technologist Group & NaNoWriMO group \\
\hline Creative Technologist Group & VVVV/Projection/Kinect group \\
\hline Gaming Group & GameJam \\
\hline
\end{tabular}

Table 1: A sample of community groups at MadLab

MadLab's distinctive openness to working with other organisations (Table 2) also reveals an intersection of organisational situations. MadLab is not solely working with other 'Innovating Organisations' or 'Startups' but rather draws partnerships and alliances from across a wide spectrum of organisations with varying emphasis and levels of strategic, visionary and operational management. This produces an internal organisational strength that also offers opportunities for longer term strategic sustainability.

\begin{tabular}{|l|l|}
\hline Organisational Situation & Organisation \\
\hline Institution/Academic Artefact & Manchester Digital Development Agency \\
\hline Big Government & Manchester City Council \\
\hline Institution & Manchester Library Service \\
\hline Institution/Innovating Organisation & University of Lancaster \\
\hline
\end{tabular}

Table 2: A sample of external partner organisations and groups working with MadLab

\section{Analysis and Discussion}

A pivotal observation drawn from an examination of MadLab is that neat distinctions of organisation, vision and prototype can easily collapse, and that the resultant discussion can demand more nuanced observations. MadLab's description as an 'organisation as prototype' cannot be considered as the exclusive pathway or essential guide to creative space 
organisational success. However as an 'organisation as prototype' Madlab does provide insight and clarification into the complex relationship requirements needed when managing a creative space and the relational interplay observed when a creative space must balance inspiration, operation and strategy (figure 1) within its ongoing daily activities. The vignette presented in this work is developed through reflective empirical research in collaboration with the four directors of MadLab who are involved in the facilitation and management of creativity within the organisation and their community. Our goal was to bring to bear an appreciation of the intersecting complexities of the context of the creative workspace that is MadLab, of the forms of management that 'work' in a space of this type with the goal of producing a feedback loop back to the directors and MadLab itself.

A key aspect of this feedback loop is the importance of articulating a strategy for creating MadLab 'as organisation' and to take it from being 'organisation as prototype'. We characterise strategy formation in an organisation such as MadLab to be a research act that analyses experiential data incrementally emerging from the forms of management that coexist and interact within MadLab. In particular, the strategic view of MadLab is not absent but rather imminent, embedded within stories of success and prior achievements and largely curated through existing websites, blogs and videos. This is an experience of many visionary organisations and the challenge for many small enterprises in becoming sustainable. The ability to consciously recognise this strategic capacity from existing activity requires reflexivity and a form of self-critique that is beyond the capability of a self-initiated project.

In this paper we extend the discussion and the model offered in Bell et al (2013) (Figure 1) by considering MadLab as an 'organisation as prototype' that itself tests the visionary management and inspirations of the four directors; initially personally and then later, relationally, within the organisational form of MadLab. For MadLab 'as prototype' the inspiration brought by science- 
and speculative-fiction as well as other influences continuously become incorporated into the prototype through the individual knowledge, skills and experiences of the four directors. We claim that within the indefinite space of visionary management is necessarily found the continuous accretion of the sources and drivers for innovation expressed initially as personal knowledge and skills that ultimately, or at least hopefully, become consolidated, articulated and re-articulated within an organisation. Papanek (1985) recognises this complexity by outlining what he labels as creative thinking he says, "neither psychologists nor the innovators themselves have a clear explanation of this process" (Papanek 1985: 152). Innovation and visionary management is never a fully formed organisational state that can be extracted precisely. Papanek's (1985: 152) separation of different forms of thinking similarly echoes the model presented here (Figure 1) with his 'analytical thinking' mirroring strategic management and judgmental and routine forms of thinking aligning with what is described as operational management.

In MadLab this condensing of talent, inspiration and innovation as vision represents the construction of the 'organisational prototype' itself and reveals the fuzziness and feedback loop that is present between visionary management and prototyping. Prototypes test the strength and purpose of visionary management and clarify organisational vision. As a result these prototypes can - and should - offer guidance to the operational and strategic aspects of an organisation's management. This observation reveals the potential dichotomy of future strategic direction within a flexible organisational form that adheres to the heritage and experience of organisational formation. For the innovating organisation, such as MadLab, the consequence and dangers of being an artefact of their original vision may be expressed as an inability to become strategically sustainable. For MadLab, the point at which innovation and vision became expressed as prototype can be specifically identified as the happenstance coalescence of the four directors and their overlapping but distinct skill sets that cross over in multiple ways 
between the arts and sciences. The ongoing testing of the director's individual and collective organisational vision is articulated in the development and evolution of MadLab 'as organisation'.

MadLab also represents a continuously iterative and self-referential form of prototyping. The organisational prototype - MadLab - inspires, supports and homes further organisational prototypes that focus on and are drawn together by specific combinations of interests that also draws upon MadLab as inspiration. MadLab begets mini-MadLabs in the form of the various groups that work through the space with an innovative form of organisational vision that is potentially organically self-perpetuating. The operational model provided in this way frees up the emerging organisations to more clearly focus on creativity and the prototyping of ideas, products, services and still more organisations. Ultimately the success of this prototype will be measured by organisations that eventually leave the MadLab space entirely to create their own spaces and thus further perpetuate this form of 'organisation as prototype' elsewhere. Or by the innovative products and solutions that emerge from collaborations hothoused at Madlab.

This iterative process necessitates understanding of the relationship of visionary, strategic and operational management within MadLab. MadLab reveals aspects of these forms of management in the production of different artefacts and events. The organisational prototype, in its operational form, that is used by groups working with MadLab provides the mechanism for managing their formation and ongoing activities. Importantly, it is at this level of operational management that value creation occurs through the exertions of labour among the directors, the group leaders (known within MadLab as 'Melders') and volunteers as well as guest speakers and demonstrators. The imminent and continually developing practices of strategic management at MadLab is evidenced, for example, through the website where case studies and descriptions of previous successful activities are presented. These are important scenarios for strategic success that are known - by MadLab - to the current moment in time. The strategic 
level of understanding at MadLab expressed in this way offers explication of the potential mechanisms for ongoing organisational sustainability. However, Madlab, as with any small enterprise, faces the challenges of sustainability and this includes recognition that successful scenarios test organisational strategy rather than being simply descriptions of previous operational activities. The inter-relationship of operational, strategic and visionary forms of management highlight the need, for constantly iterative interactions between each form of management and for the organisation to remain innovative while still continuing to create value in a manner that is sustainable in the broadest organisational sense.

Our extension to the relational model of forms of management proposed in Bell et al. (2013) assists in explaining the relationship between visionary management, personal inspiration and prototypes of an organisation. Imbalances in the 'triangle' revealed through a lack of articulation or, at the extreme, an absence of one form of management offers a generalised mechanism for recognising the situations that different forms of organisations regularly find themselves (Table 3). The absence of one or more form of management may be identified as a basic failure to communicate, a common complaint that occurs between operational and strategic management, or of a complete absence, often of visionary management. This extrapolation of the potential imbalances that can develop in the relational model assist in positioning MadLab's current situation as well as understanding other organisations with which MadLab regularly interacts. This analysis assists in revealing the rationale for these many intra-organisational relationships and is indicative of the desire by one or both parties to engage with organisations of a different 'type'. The current success of MadLab 'as prototype' can, at least in part, be recognised by the willingness to interact with the widest range of other 'types' of organisations. The willingness for interaction at the widest range enables all to extract mutual benefit and value from each other. 


\begin{tabular}{|c|c|c|l|}
\hline Operational & Strategic & Visionary & Organisational situation/Types of organisation \\
\hline $\mathrm{Y}$ & $\mathrm{N}$ & $\mathrm{N}$ & $\begin{array}{l}\text { Small-Medium Enterprise (SME): Resources fully } \\
\text { committed to operational activities. Reluctance to } \\
\text { commit resources to non-operational activities. Lack } \\
\text { of internal recognition of existing strategic } \\
\text { capabilities }\end{array}$ \\
\hline $\mathrm{N}$ & $\mathrm{Y}$ & $\mathrm{N}$ & $\begin{array}{l}\text { Big Government: Lack of attention to operational } \\
\text { details or reality combined with an inability to } \\
\text { genuinely or rapidly innovate }\end{array}$ \\
\hline $\mathrm{N}$ & $\mathrm{N}$ & $\mathrm{Y}$ & $\begin{array}{l}\text { (Failed) Startup: Full of innovation and concepts. } \\
\text { The 'classic' example that good ideas do not } \\
\text { necessarily equate to organisational or commercial } \\
\text { success }\end{array}$ \\
\hline $\mathrm{Y}$ & $\mathrm{Y}$ & $\mathrm{N}$ & $\begin{array}{l}\text { Institution: Traditional organisational model } \\
\text { including the potential for burdensome committees. } \\
\text { Well established structures and levels of } \\
\text { management with differentiated responsibilities. } \\
\text { Slow to innovate and when this occurs it falls } \\
\text { outside' existing process (and as such is critically } \\
\text { received) }\end{array}$ \\
\hline $\mathrm{Y}$ & $\mathrm{N}$ & $\mathrm{Y}$ & $\begin{array}{l}\text { Academic Artefact: Conceptualised perspective of } \\
\text { the organisation that is largely disconnected from } \\
\text { operational reality. Sustainable and innovative in } \\
\text { principle but without the mechanisms to function on } \\
\text { a day-to-day basis }\end{array}$ \\
\hline $\mathrm{N}$ & $\mathrm{Y}$ & $\begin{array}{l}\text { Innovating Organisation: Driven by visionary } \\
\text { management and functioning through the practical } \\
\text { application of the prototype at an operational level }\end{array}$ \\
\hline
\end{tabular}

Table 3: Type of organisations highlighting imbalances and barriers to innovation and sustainability within organisations

The temptation in the analysis of a specific organisation is to identify the 'missing link' and endeavour to add - or even impose - a particular form of 'missing' management into the organisation. For example, MadLab 'as organisation' can be identified as an 'Innovating Organisation' that has overcome the dangers of being a '(Failed) Startup' but is yet to become a 
fully balanced sustainable organisation. Much of the mainstream organisational drive towards crowdsourcing and open innovation can be explained in light of this categorisation offered in Table 3 as organisations that do not have a visionary form of management seek to remedy their absence of innovation by performing a form of tacit outsourcing. Many of MadLab's intraorganisational partnerships could be argued to support this rationale. However, the barrier to this approach becoming a long term solution is identifiable as a key element of the internal relationship between forms of management presented in Figure 1. This relationship model emphasises the presence and need for ongoing iterative interaction between each of the forms of management within the organisational while also remaining permeable and responsive to external organisations, changes, influences and inspirations. This claim is specifically in contrast to Kaivo-oja, Katko and Seppälä's (2004) view of visionary management in which they present a temporal relationship between forms of management that suggests no direct communication is found between the operational and the visionary form of management.

\section{Conclusion: MadLab an 'organisation as prototype'}

MadLab offers insight on an academic level by presenting mechanisms for the examination of other organisations and their relationship to visionary management, by detailing the challenge many organisations have in becoming strategically sustainable. Further and in capturing internally generated inspiration to produce innovation. In practical terms, as a prototype for other organisations, the description and discussion of MadLab offers guidance for establishing other 'innovating organisations' where aspirations exist for achieving long-term strategic sustainability. There are unarguably unique and personal qualities that the four directors bring to the story of MadLab that cannot be replicated in a different venue, however, much can be taken from the social and organisational aspects of MadLab particularly when they are read through the interpretative devices presented in Figure 1 and Table 3. 
While the research set out to identify the specific influences of science fiction or speculative fiction on the 'organisational prototype', what was revealed was a complex bricolage of circumstances that draws upon many literary, popular media and locational influences. Although in the MadLab case this clearly includes science fiction the specific mix of individualised aspects of an organisational prototype prevents such a conclusive meta-narrative of single association that might be possible in the discussion of a specific material product. Science fiction's prevalent, but often layered, social and organisational commentary is reflected in MadLab in the underlying unwritten principles of association and conduct. The directors are collectively certain that they are inspired by science fiction - and are familiar with a significant range of 'classic' authors as well as a range of seminal graphic novels. However, when pushed the directors cannot identify these relationships directly, speculatively in part, because the science fiction inspirations they are working with are so deeply internalised. The science fiction inspiration is best expressed as being part of the unique contribution that each director brings to their innovation and the 'organisation as prototype'. Personal history and influences are an inescapable reality of inspiration and are among the unique parameters that feed into the realisation of innovation.

More significantly, for the organisational prototype and as a repeatable parameter for other organisations is the extent to which intra-organisational working and collaboration occurs at MadLab. MadLab is a permeable organisation that is open to new people, ideas and other organisations. This permeability brings a continuous inward flow of ideas and inspiration that are brought into the organisation and into communication with all forms of management. The potential issues of capacity, capability and the limits brought by this openness are yet to be reached but will eventually emerge. Reaching this limit, it can be presumed, will be necessitated by increasing attention to strategic management issues that will act as a filter to external input and come to define the basis for long-term collaborations. 
MadLab's self-referential model of organisation is a distinctive but repeatable feature of the prototype. Ultimately the mechanism for MadLab to replace itself with another organisation either in substitution to, or as well as, is already embedded in itself. The example of the way in which MadLab brought a science-fiction reading group into the organisation that in turn provided the pathway for the speculative writing group is small evidence of a cycle that can be undertaken indefinitely under a range of different banners and collections of interests.

The openness of MadLab's directors to discussing and presenting MadLab to any audience is a further distinguishing feature that represents a repeatable parameter found in the 'organisation as prototype'. Many of the alliances and associations that are currently active have come through this marketing work and evidenced in the range of materials that are publicly available (Section 7). As an innovating organisation the directors have a message that finds a ready audience at a variety of forums. This is best understood in terms of the varying balance of management found in the types of organisation described in Figure 3 and in particular those that are different to the innovating organisation that is MadLab.

To borrow a concept from the computer scientists, a design pattern is evident in our observations of MadLab. The principle of the design pattern is that this is not a prescriptive 'must have' combination of elements that must be precisely adhered to, but rather, is a contextual combination of actions that produces a broadly recognisable result. MadLab is a model of organisational Science Fiction prototyping that brings together visionary management, permeability to external organisations of different types, sensitivity to the local community, conscious engagement with the surrounding business environment and a range of personal inspirations as repeatable parameters for becoming an innovating organisation. At the same time MadLab typifies the ever present challenges that small-medium enterprises and innovating 
organisations face to be sustainable and remain viable over the longer term. Science fiction is a subtle inspiration in varying degrees for all of the directors but we describe this as part of their individual backgrounds and inspiration. The influence of a different science fiction author on any of the four directors would have produced a different organisation but from the point of view of a design pattern that result would too have been an innovating organisation. For other organisations, application of the repeatable parameters of the design pattern guide and can contribute to their own long-term strategic sustainability.

\section{References}

1. Bell, F., Fletcher, G., Greenhill, A., Griffiths, M. \& MacLean, R., Science fiction prototypes: Visionary technology narratives between futures, Futures. 50, June, 2013, pp.5-14.

2. Alvesson, M. \& Sköldberg, K., Reflexive methodology : new vistas for qualitative research, 2nd ed, SAGE, London, 2009.

3. Amabile, T. M., Creativity in context: update to the social psychology of creativity, Westview Press, Oxford, 1996.

4. Dourish, P. \& Bell, G., Resistance is Futile: Reading science fiction alongside ubiquitous computing, www.dourish.com/publications/2009/scific-puc-draft.pdf, 2009, accessed $31 / 10 / 2012$.

5. Ferneley, E. \& Bell, F., Using bricolage to integrate business and information technology innovation in SMEs, Technovation, 26(2), 2006, 232-241.

6. Johnson, B., Science Fiction Prototyping: designing the future with science fiction, Morgan and Claypool, San Francisco, 2011.

7. Kaivo-oja, J. Y., Katko, T. S. and Seppälä, O. T., Seeking convergence between history and futures research". Futures, 36(5), 2004, pp.527-547.

8. Livingstone, I. \& Hope, A., Next Gen. NESTA, 2011, www.nesta.org.uk/publications/assets/features/next_gen, accessed 15/11/2012.

9. Mannermaa, M., In search of an evolutionary paradigm for futures research. Futures, 23(4), 1991, pp.349-372.

10. Mintzberg, H., Patterns in Strategy Formation, Management Science, 24(9), 1978, 934-948.

11. Mintzberg, H., The Strategy Process: concepts, contexts, cases The Strategy Process : concepts, contexts, cases, 4th ed, Pearson Education, Harlow, 2003.

12. Mintzberg, H., Ahlstrand, B. \& Lampel, J., Strategy safari: a guided tour through the wilds of strategic management, The Free Press, New York, 1998.

13. Papanek, V., Design for the Real World: Human Ecology and Social Change, Thames and Hudson, London, 1985.

14. Sauer, C. \& Willcocks, L., Establishing the Business of the Future: The role of organizational architecture and information technologies, European Management Journal, 21(4), 2003, 497-508. 
15. Shalley, C. E. \& Gilson, L. L., What leaders need to know: A review of social and contextual factors that can foster or hinder creativity, The Leadership Quarterly, 15(1), 2004, 33-53.

16. Weick, K., Making Sense of the Organisation, Blackwell, Oxford, 2001.

17. Woodman, R. W., Sawyer, J. E. \& Griffin, R. W., Toward a Theory of Organizational Creativity. The Academy of Management Review, 18(2), 1993, 293-321.

\section{MadLab social media, videos and reporting}

Bull, C., DIY CSI in MCR, 28th May, 2012, chrisbullphotographer.blogspot.co.uk/2012/05/diycsi-in-mcr.html, accessed 10/11/2012.

Calow, A., Manchester's MadLab spends time with the FBI, The Guardian, 18th June, 2012, www.guardian.co.uk/uk/the-northerner/2012/jun/18/manchestermetropolitanuniversitybiology-diybio-madlab-fbi-california-conference, accessed 10/11/2012.

Calow, A., DIYbio Manchester. 2012, http://asacalow.co.uk/, accessed 10/11/2012.

Coral, Five on a Friday with ... MadLab's Hwa Young Jung, innovator and fairy geek mother.Capital Relations. 4th March, 2011, capitalrelations.co.uk/2011/03/04/five-on-afriday-with-madlabs-hwa-young-jung-innovator-and-fairy-geek-mother/, accessed 10/11/2012.

Catalyst Citizens, Asa Calow talks Patchwork. 13th June, 2012, www.youtube.com/watch?v=g_RAFbXOeQo, accessed 10/11/2012.

Diyhpluswiki, Experiences in Journalism diyhpl.us/wiki/transcripts/fbi-diybio-2012/rachael-turnermadlab.txt, 2012, accessed 10/11/2012.

Diyhpluswiki, MadLab, diyhpl.us/wiki/transcripts/fbi-diybio-2012/madlab.txt, 2012, accessed 10/11/2012.

Fabretti, P., MadLab hackspace opening soon, everyone's invited, How-do, 18th Sept, 2009, www.how-do.co.uk/north-west-media-news/other-media/madlab-hackspace-openingsoon,-everyone's-invited-200909186374/, accessed 10/11/2012.

File on 4, BioSecurity - As scientists alter viruses to make potentially deadly mutations, is the public at risk? Radio 4, 7th February, 2012, www.bbc.co.uk/radio/player/b01blzkx, accessed 10/11/2012.

Manchester Evening News, Madlab scientists invited to advise the FBI on DIY biology. 27th May, 2012, menmedia.co.uk/manchestereveningnews/news/s/1538103_madlab-scientistsinvited-to-advise-the-fbi-on-diy-biology, accessed 10/11/2012.

Mee, D., The Arduino Lab Project, Digital Media Art MediaCityUK, creativetechnology.salford.ac.uk/projectspace/, accessed 10/11/2012.

Mee, D., Dave Mee here! http://davemee.com/, accessed 10/11/2012.

O'ReillyGMT, Dave Mee - Madlabs, 13th Oct, 2009, www.youtube.com/watch?v=hn8avhm9e9o, accessed 10/11/2012.

Pendrill, J., Manchester's Digital Landscape: Hwa Young (Mad Labs), Transforming Management, Manchester Business School, 6th Feb, 2012, www.youtube.com/watch?v=whcYPP1bFWk, accessed 10/11/2012.

Sale, C., Interview: Hwa Young Jung, Manchester Digital Laboratory, NetSquared, 2012, www.netsquared.org/blog/interview-hwa-young-jung-manchester-digital-laboratory, accessed 10/11/2012. 
Shukman, D., Early days in a DIY biological revolution, BBC Science and Environment, 28th Mar, 2012, www.bbc.co.uk/news/science-environment-17511710, accessed 10/11/2012.

Schürholz, F., Coworking in Manchester - Manchester Digital Laboratory - a 'Cultural Capital Space', 2012, www.coworking-news.de/2012/02/coworking-in-manchester-manchesterdigital-laboratory-a-cultural-capital-space/, accessed 10/11/2012.

Tequals0, DIYBIO - FBI Outreach Conference, San Fransico. 24th June, 2012, tequals0.wordpress.com/2012/06/24/diybio-fbi-outreach-conference-san-fransisco/, accessed 10/11/2012.

Wrenn, E., Once in a lifetime: Transit of Venus puts on spectacular show for the last time until 2117. The Mail Online. 7th June, 2012, www.dailymail.co.uk/sciencetech/article2155140/Transit-Venus-2012-Spectacular-seen-time-2117.html, accessed 10/11/2012. 